\title{
Association of Work Stress Level with Sleep Quality in Nurses and Medical Social Workers at a Tertiary Care Hospital of Wardha District
}

\author{
Vikram Singh ${ }^{1}$, Pramita Muntode², Sonal Singh ${ }^{3}$, Rutuj Waghmare ${ }^{4}$, Sumit Kishore ${ }^{5}$, Shobha Joshi ${ }^{6}$, Rahul Thakur $^{7}$ \\ 1, 2, 4, 5, 6,7 Department of Community Medicine, Datta Meghe Institute of Medical Sciences, Sawangi (M), \\ Wardha, Maharashtra, India, District Consultant NTCP, District Durg, Chhattisgarh, India.
}

\section{ABSTRACT}

\section{BACKGROUND}

Nurses and medical social workers' (MSW's) stress has an impact on health, which ultimately has an effect on quality care of the patients. Stress problems are one of the leading causes of sleep disturbance. We wanted to evaluate the association of quality and pattern of sleep with work stress levels in nurses and medico-social workers in this study.

\section{METHODS}

A cross-sectional study was conducted on nurses and MSW's of Tertiary Care Hospitals of Wardha city using questionnaire, containing 24 questions. A total of 513 Nurses and 36 MSW's of Tertiary Care Hospitals were taken in this study, sampling was done by simple random sampling method. The stress was evaluated using 10 items "Global perceived stress scale" (GPSS) and for sleep quality "Pittsburgh Sleep Quality Index" (PSQI) of total 14 items was used. The variables were compared in unpaired t test and Pearson correlation test to know the level of significance of determinacy which was set at less than 0.05 .

\section{RESULTS}

The overall PSS scores in nurses $(12.57 \pm 3.7)$ and MSWs $(12.87 \pm 3.1)$ were almost similar and were statistically significant. Subjective sleep quality score of MSWs (2.19 $\pm 0.66)$ was higher than that of nurses $(2.00 \pm 0.19)$ and was statistically insignificant according to the specialization. The statistically relevant sleep duration was greater in MSWs $(13.50 \pm 03.56)$ than in nurses $(12.16 \pm 02.73)$. Moderate positive correlation between perceived stress severity and Pittsburgh Sleep Quality Index was observed.

\section{CONCLUSIONS}

Certain characteristics of work shift among nurses and MSW's is directly affected by the stress and sleep quality and indirectly affects the patient care and treatment. The study indicates that work characteristics may influence sleep quality and stress among nurses and MSW's. We needed to improve work shift schedule in order to provide good health and well-being of nurses and MSW's which would further improve the quality of patient care.

\section{KEY WORDS}

Nurses, MSW's, Sleep Quality, Stress

\author{
Corresponding Author: \\ Dr. Vikram Singh, \\ Department of Community \\ Medicine, Datta Meghe Institute of \\ Medical Sciences, Sawangi (M), \\ Wardha, Maharashtra, India. \\ E-mail: rutujwaghmare4@gmail.com
}

DOI: $10.14260 /$ jemds/2021/422

How to Cite This Article:

Singh $V$, Muntode $P$, Singh $S$, et al. Association of work stress level with sleep quality in nurses and medical social workers at a tertiary care hospital of Wardha District. J Evolution Med Dent Sci 2021;10(28):2061-2065, DOI: $10.14260 /$ jemds/2021/422

Submission 21-10-2020,

Peer Review 12-05-2021,

Acceptance 19-05-2021,

Published 12-07-2021.

Copyright (C) 2021 JEMDS. This is an open access article distributed under Creative Commons Attribution License [Attribution 4.0 International (CC BY 4.0)] 


\section{BACKGROUND}

One fifth of the working population is estimated to do a job in different working times or at night. Night shift is frequent in health sectors. ${ }^{1}$ In many professions in modern society, shift work structures are increasingly becoming a common concept. A number of employees working in shifts as part of their contract of employment are increasing nowadays. Due to the need in business, continuous production and 24-hour services are required, mainly for this shift work pattern. People are therefore expected to work at all hours regardless of day. ${ }^{2}$ Working in shifts is generally used to define a variety of work schedules which include: ${ }^{1}$ working in night shifts, ${ }^{2}$ Shift overtime or longer hours of work. $^{3}$ Job habits repetitive or rotative and 4 non shift schedules relating to the hours worked. ${ }^{3}$ Nursing is the largest profession in health care in terms of staff and shifts of job have a significant effect on the nursing profession. The crucial part of nurses' work environment is that they need to provide uninterrupted treatment 24 hours a day. To hospital nurses who consider patients in need, rotating shift work is both natural and appropriate. Nonetheless, rotating shift work has been reported to be linked with a number of health problems which have caused serious negative effect on the nurse's health status, but have also shown an impact on patient care. ${ }^{4}$ Good quality sleep is crucial for the health and well-being of an individual. One of human basic needs is sleep and rest. Sleep is imposed as a physiological need upon Maslow's hierarchy of needs. Sleep offers a chance to reenergize and relieve the human body from stress.

Nurses are among the largest group of professionals in the health care sector. During morning, afternoon, and night shifts, nurses and MSWs work irregularly, so they are at high risk of insomnia complications. A large number of nurses experience medical errors each year due to drowsiness that leads to serious injury to patients. The correlation between sleep disruption and nursing errors has been demonstrated in several studies. There is inefficient functioning of MSWs due to sleep disturbance. There are several occupational and individual factors negatively affecting sleep quality of nurses \& MSWs. ${ }^{5}$

Therefore, it was very important to consider and research the impact of the work characteristics of nurses and MSWs and their association with sleep quality and stress due to their work profile and with this background study was conducted at tertiary care hospitals of Wardha city.

\section{METHODS}

This cross-sectional study was conducted on nurses and MSW's working at tertiary care hospitals of Wardha city. A total of 513 nurses and 36 MSW's were taken for this study, sampling was done by simple random sampling method. Study was approved by "Institutional Ethical Committee" (DMIMS (DU) / IEC / sep2019 / 8321) and informed consent was taken from all the study participants. Data was collected by a single person during the entire period providing instructions on filling questions. A period of 30 minutes was given for filling the questionnaires. The components in the questionnaire were: Demographic component, Global perceived stress scale
(PSS) and the Pittsburgh Sleep Quality Index (PSQI) was given to nurses and MSW's. The demographic component included age, gender \& work shift.

Fourteen questions were asked for stress evaluation and ten questions were asked for sleep evaluation of nurses and MSW's. The Perceived Stress Scale [PSS] containing 14 questions is a typical stress assessment tool which helps us to understand how different conditions affect one's feeling and perceive stress.

Hence, it remains a popular choice. The advantage of Perceived Stress Scale is that it can be applied to different types of subjects, wide range of settings, while the other reviewed stress scales for medical professional workers focus only on stress of academics.6,7

PSQI evaluates various factors related to sleep quality in the last one-month period. The PSQI in total consists of 7 components: subjective sleep quality, sleep latency, sleep duration, the ratio between time slept and time in bed, habitual sleep efficiency, sleep disturbances, use of sleep medication and daytime dysfunction. ${ }^{8}$

The total score which is derived from seven subscales and higher scores designate poorer sleep quality. ${ }^{8}$ The perceived stress scale was used for assessing stress, seven among the fourteen items were considered as positive $(4-7,9,10$ and 13$)$ and the other seven were considered as negative $(1-3,8,11$, 12 and 14) which represent self-efficacy and perceived helplessness, respectively. ${ }^{9}$

The above item was rated on Likert type scale of 5 - point $(0=$ never to $4=$ very often $)$. Total 14 item scores were obtained by first reversing the score of positive item and then adding all the scores to calculate global perceived stress.

\section{Statistical Analysis}

Descriptive analysis was carried out in order to evaluate the measures of the collected result. After organizing the data, it was stored in spread sheet in Windows XP, Excel 2007 program and statistical analysis was conducted on the SPSS version 21. Quantitative variables were compared in unpaired t test and correlation.

\section{RESULTS}

\begin{tabular}{|c|c|c|c|}
\hline \multicolumn{2}{|c|}{ Variable } & $(\mathrm{N}=549)$ & $\%$ \\
\hline \multirow{2}{*}{ Sex } & Male & 48 & 8.4 \\
\hline & Female & 501 & 87.7 \\
\hline \multirow{4}{*}{ Age } & $19-28$ & 93 & 16.93 \\
\hline & $29-38$ & 241 & 43.89 \\
\hline & $39-48$ & 186 & 33.87 \\
\hline & $49-60$ & 29 & 5.28 \\
\hline \multirow{4}{*}{ Marital Status } & Single & 131 & 23.86 \\
\hline & Married & 388 & 70.67 \\
\hline & Divorced & 18 & 3.27 \\
\hline & Widowed & 12 & 2.18 \\
\hline \multirow{3}{*}{ Education } & Diploma & 194 & 35.3 \\
\hline & Graduate & 269 & 48.8 \\
\hline & Post-graduate & 86 & 15.7 \\
\hline \multirow{2}{*}{ Occupation } & Nurses & 513 & 93.3 \\
\hline & MSW & 36 & 6.6 \\
\hline \multirow{2}{*}{ Shift Duties } & Day shift & 398 & 72.4 \\
\hline & Night shift & 155 & 28.2 \\
\hline
\end{tabular}

Table 1 shows demographic characteristics of 549 tertiary care hospital nurses and MSWs of which 8.4 percent were 
males and 87.7 percent were females, most participants were in the age group of $29-48$ yrs. and most of them were graduates. Most of the current research participants were married. 93.3 per cent of participants served as nurses and 6.6 per cent as MSWs, 72.4 per cent had day shift duties and 28.2 per cent had night shift duties.

\begin{tabular}{|cccc|}
\hline Variables & $\mathbf{N}$ & Mean & Std. Deviation \\
Positive PSS & 549 & 10.98 & 2.89 \\
Negative PSS & 549 & 5.03 & 1.58 \\
Total PSS & $\mathbf{5 4 9}$ & $\mathbf{1 6 . 0 1}$ & $\mathbf{4 . 4 7}$ \\
Subjective sleep quality & 549 & 2.24 & 0.72 \\
Sleep latency & 549 & 1.47 & 0.52 \\
Sleep duration & 549 & 2.16 & 0.77 \\
Habitual sleep efficiency & 549 & 1.94 & 0.83 \\
Sleep disturbances & 549 & 2.63 & 0.52 \\
Use of sleeping medication & 549 & 1.02 & 0.85 \\
Daytime dysfunction & 549 & 2.41 & 0.62 \\
Total PSQI Score & $\mathbf{5 4 9}$ & $\mathbf{1 3 . 8 5}$ & $\mathbf{4 . 8 3}$ \\
\hline Table 2. Description of Overall Perceived Stress Scale (PSS) Scores \& \\
Overall Pittsburgh Sleep Quality Index (PSQI) Scores \\
Amongst the Study Participants \\
\hline \multicolumn{4}{c}{} \\
\hline
\end{tabular}

Table 2 indicates a mean overall PSS value of $16.01 \pm 4.47$. The mean positive PSS score was $10.98 \pm 2.89$, and it was 5.03 \pm 1.58 for negative PSS score. Total PSQI scores were $13.85 \pm$ 4.83 .
The factor with the highest mean score was sleep disturbance (2.63 \pm 0.52$)$, and use of sleep medication (1.00 \pm 0.85 ) was having lowest mean score.

Table 3 shows the further division of Specialization, Working Shifts and Sex PSS ratings Work Shift pattern of participants. The overall PSS scores in Nurses $(12.57 \pm 3.7)$ and MSWs $(12.87 \pm 3.1)$ were nearly identical, and were statistically significant.

The positive PSS score for Nurses $(5.07 \pm 1.6)$ and MSWs $(5.08 \pm 1.2)$ and the negative PSS score for Nurses $(7.5 \pm 2.10)$ and for MSWs $(7.75 \pm 1.9)$ respectively. For males and females, the overall PSS ratings were almost equal $(12.87 \pm 3.36$ and $12.66 \pm 3.70$ ) and were not statistically significant.

The females reported higher scores for Negative PSS scores $(7.79 \pm 2.13)$ than males $(6.59 \pm 1.9)$, and this difference was also statistically insignificant.

Slight difference was reported for Positive PSS ratings, with males getting marginally higher scores $(5.08 \pm 1.23)$ than females $(5.07 \pm 1.60)$ which was again statistically insignificant.

Nevertheless, the females showed higher scores for Negative PSS scores $(7.79 \pm 2.13)$ than males $(6.59 \pm 1.9)$, and this difference was statistically insignificant.

\begin{tabular}{|c|c|c|c|c|c|c|c|c|c|}
\hline Variables & $\begin{array}{c}\text { Nurses } \\
(N=513)\end{array}$ & $\begin{array}{c}\text { MSW } \\
(N=36)\end{array}$ & P - Value & $\begin{array}{c}\text { Male } \\
(N=48)\end{array}$ & $\begin{array}{c}\text { Female } \\
(N=501)\end{array}$ & P - Value & $\begin{array}{c}\text { Day Shift } \\
\text { Duties } \\
(\mathrm{N}=398)\end{array}$ & $\begin{array}{l}\text { Night Shift } \\
\text { Duties } \\
(N=151)\end{array}$ & p - Value \\
\hline & Mean \pm SD & Mean \pm SD & & Mean \pm SD & Mean \pm SD & & Mean \pm SD & Mean \pm SD & \\
\hline Positive PSS & $5.07 \pm 1.6$ & $5.08 \pm 1.2$ & 0.11 & $5.08 \pm 1.23$ & $5.07 \pm 1.60$ & 0.12 & $5.10 \pm 1.54$ & $4.78 \pm 1.64$ & $0.03^{*}$ \\
\hline $\begin{array}{l}\text { Negative } \\
\text { PSS }\end{array}$ & $7.5 \pm 2.10$ & $7.75 \pm 1.9$ & 0.18 & $6.59 \pm 1.90$ & $7.79 \pm 2.13$ & 0.18 & $7.71 \pm 2.05$ & $7.09 \pm 2.06$ & $0.04^{*}$ \\
\hline Total PSS & $12.57 \pm 3.70$ & $12.87 \pm 3.1$ & $0.02 *$ & $12.87 \pm 3.36$ & $12.66 \pm 3.70$ & 0.22 & $11.81 \pm 3.7$ & $12.87 \pm 3.59$ & $0.04 *$ \\
\hline \multicolumn{3}{|c|}{ Nurses } & \multirow{2}{*}{\multicolumn{2}{|c|}{ P - Value }} & \multirow{2}{*}{\multicolumn{4}{|c|}{ MSWs }} & \\
\hline Variables & $\begin{array}{l}\text { Day Shift } \\
(\mathrm{N}=371)\end{array}$ & $\begin{array}{l}\text { Night Shift } \\
(\mathrm{N}=142)\end{array}$ & & & & & & & $\mathrm{p}$ - Value \\
\hline Positive PSS & $5.16 \pm 1.56$ & $4.85 \pm 1.65$ & \multicolumn{2}{|c|}{$0.04^{*}$} & \multicolumn{2}{|c|}{$4.40 \pm 1.65$} & \multicolumn{2}{|c|}{$4.22 \pm 2.10$} & $0.04^{*}$ \\
\hline Negative PSS & $7.73 \pm 2.09$ & $7.14 \pm 2.05$ & \multicolumn{2}{|c|}{$0.02 *$} & \multicolumn{2}{|c|}{$6.96 \pm 1.88$} & \multicolumn{2}{|c|}{$6.44 \pm 2.65$} & 0.17 \\
\hline Total PSS & $12.89 \pm 3.65$ & $11.99 \pm 3.7$ & \multicolumn{2}{|c|}{ 0.04* } & \multicolumn{2}{|c|}{$11.36 \pm 3.53$} & \multicolumn{2}{|c|}{$10.66 \pm 4.75$} & 0.21 \\
\hline
\end{tabular}

\begin{tabular}{|c|c|c|c|c|c|c|}
\hline Variables & $\begin{array}{l}\text { Nurses }(\mathrm{N}=513) \\
\text { Mean } \pm \text { SD }\end{array}$ & $\begin{array}{c}\text { MSWs }(\mathrm{N}=36) \\
\text { Mean } \pm \text { SD }\end{array}$ & P - Value & $\begin{array}{l}\text { Male }(\mathrm{N}=48) \\
\text { Mean } \pm \mathrm{SD}\end{array}$ & $\begin{array}{c}\text { Female }(\mathrm{N}=501) \\
\text { Mean } \pm \text { SD }\end{array}$ & P - Value \\
\hline Subjective sleep quality (score) & $2.00 \pm 0.19$ & $2.19 \pm 0.66$ & 0.09 & $2.02 \pm 0.52$ & $2.26 \pm 0.74$ & 0.029 \\
\hline Sleep latency (minute) & $12.16 \pm 02.73$ & $13.50 \pm 03.56$ & $<0.001 *$ & $14.62 \pm 0.56$ & $14.39 \pm 0.51$ & $0.004^{*}$ \\
\hline Sleep duration (hours) & $6.38 \pm 2.55$ & $7.11 \pm 0.89$ & $0.007^{*}$ & $7.12 \pm 1.76$ & $6.99 \pm 1.86$ & $0.02^{*}$ \\
\hline Habitual sleep efficiency (\%) & $72.08 \%$ & $65.69 \%$ & & $81.75 \%$ & $75.95 \%$ & 0.46 \\
\hline Sleep disturbances (score) & $6.63 \pm 2.81$ & $5.54 \pm 1.48$ & $<0.001^{*}$ & $2.66 \pm 0.47$ & $6.63 \pm 3.52$ & 0.72 \\
\hline Use of sleeping medication (score) & $0.59 \pm 0.15$ & $0.19 \pm 0.12$ & 0.013 & $0.98 \pm 0.31$ & $0.16 \pm 0.06$ & 0.85 \\
\hline Daytime dysfunction (score) & $2.38 \pm 0.49$ & $2.16 \pm 0.74$ & 0.082 & $2.58 \pm 0.49$ & $2.4 \pm 0.63$ & $0.05^{*}$ \\
\hline
\end{tabular}

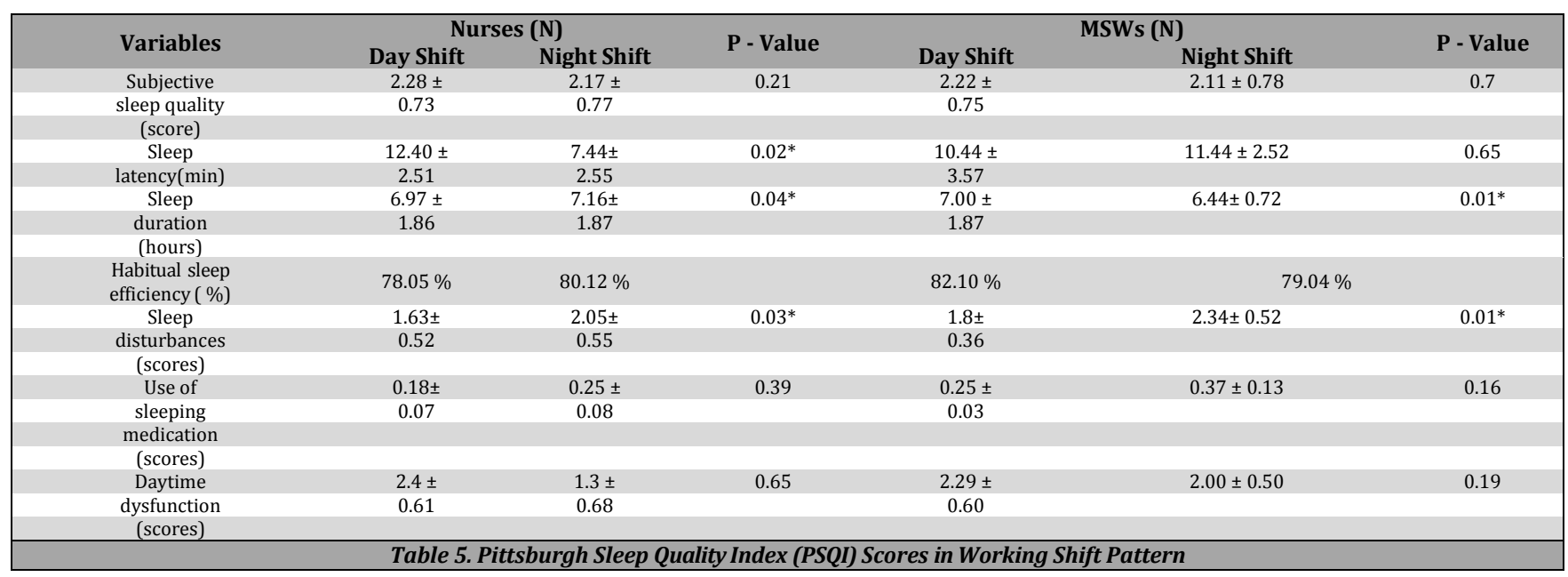


Total nurses' PSS scores were $11.81 \pm 3.7$ and $12.87 \pm$ in day and night shifts 3.59 , and statistically significant. Comparison of the PSS scores in the working shift trend of participants in which the overall day shift PSS of Nurses was marginally higher than the night shift $(12.89 \pm 3.65$ and 11.99 \pm 3.7 respectively) and was statistically important, and the day shift in MSWs also provided higher scores than the night shift $(11.36 \pm 3.53$ and $10.66 \pm 4.75$ respectively) but was insignificant.

Table 4 shows the PSQI scores for nurses and MSWs in Specialization \& Gender. Subjective sleep quality score of MSWs (2.19 \pm 0.66$)$ was higher than that of nurses $(2.00 \pm 0.19)$ and was statistically insignificant according to the specialization. The statistically relevant sleep duration was greater in MSWs $(13.50 \pm 03.56)$ than in nurses (12.16 \pm 02.73). Habitual sleep efficiency of nurses (72.08 percent) was higher than that of MSWs (65.69 percent). In nurses (6.63 \pm 2.81) sleep disturbance was greater than in MSWs (5.54 \pm $1.48)$ and was statistically important. In nurses $(0.59 \pm 0.15$ \& $2.38 \pm 0.49$ resp.) the use of sleep medication and day-time dysfunction was noticed more than in MSWs $(0.19 \pm 0.12$ \& $2.16 \pm 0.74$ resp.) and was statistically important. Daytime dysfunction was statistically important, depending on the gender sleep latency and sleep period. Habitual sleep efficiency for males was higher than the females.

Table 5 shows comparison of PSQI scores in working shift pattern of Nurses and MSWs in which sleep disturbances, sleep duration, sleep latency of nurses was found statistically significant. Daytime dysfunction, subjective sleep quality, use of sleeping medication were found statistically insignificant. For MSWs it was statistically significant for sleep duration, and sleep disturbances. Subjective sleep quality, sleep latency, use of sleeping medication \& daytime dysfunction were found statistically insignificant.

\section{DISCUSSION}

It is very important to sleep at night, which is disturbed by night shift events. There is an increased risk of sleep deprivation with mental and physical morbidity due to work on a tight schedule and changes in the pattern of the sleep wake cycle. Due to partial sleep loss, research carried out on professionals working in a tight schedule found a high percentage of errors during work. Various neurophysiological and psychological imbalances result in sleep disturbances i.e. reduction in alertness and mood fluctuations which have direct effect on an individual's performance. Owing to stress that induces depression in workers, researchers have shown a strong link between sleep disruption and insomnia. The results of this study indicated that perceived frequency of stress has been substantially correlated with greatly reduced sleep quality. The findings were consistent with previous research conducted among Norwegians and Koreans. Workload and work shifts impact directly on an individual's sleep quality and stress. In our study, we found that, according to the PSQI scale, 85 per cent of subjects had poor sleep quality. Similar study on the effect of stress on the quality of sleep was seen among young adult medical students which showed that $58 \%$ of all subjects had low quality of sleep. Van Laethem et al.10 found that Swedish workers had associated high exposure to job demands with poor sleep. Johannessen and Sterud ${ }^{11}$ found that a higher level of social support was correlated with a lower risk of male sleep problems. Kim et al. ${ }^{5}$ indicated that work related stress such as high demand for employment and lack of recompense was correlated with sleep disorders. Chazelle et al. ${ }^{12}$ found that an increased level of sensitivity to psychological demands independently predicted an increased risk of sleep disruptions among French employees.

Our tests showed that the quality of sleep was not substantially different for male and female nurses and MSWs. Male and female nurses and MSW's may have been subject to equal pressures. Gender has not substantially altered the connection between stress and sleep. The workload was comparatively equal on both male and female nurses and MSWs. However, gender was a significant factor in perceived stress in students and the perceived stress of the female students was more than male cases in another study done on Paramedical and Medical Students.13,14 Sex is a crucial determinant of mental health in most relevant surveys and female medical students suggested that they were more vulnerable to mental disorders during their study, primarily because of their instinctive characteristics and social circumstances. ${ }^{14,15}$ In comparison, a study carried out in Norway among the general workforce found that men had more work-related stress than women who expected the risk of sleep disorder. Different findings were recorded by another study on the Korean working population, which also found that men had more work-related stress than women who expected the risk of sleep disorder. The findings of the general labour force may not be specific to physicians. More law enforcement studies are required to investigate whether a sex - specific correlation of sleep stress is present or not. Our findings are reminiscent of Caruso et al. study in which the authors found that extended working hours ( $>40 \mathrm{~h} /$ week) were correlated with disease and mortality data. ${ }^{14}$ Another study emphasized that sensitivity to long hours of work was reflected in physiological (decreased immune response) and behavioural changes (decreased sleep hours). Recent studies also indicate the adverse effects of long working hours with length and consistency of the sleep. ${ }^{16}$ Literature data indicated the correlation between long hours of work and a higher prevalence of metabolic syndrome and weight gain, as well as an increased occurrence of coronary heart disease and depressive symptoms.

\section{CONCLUSIONS}

This research found that nurses with shift work suffer strongly from poor sleep quality, participants with night shift duties had low sleep quality compared to participants with day duty. Sex, age, years of work experience, and nursing department have no major impact on this issue.

There is a great need to conduct new research with a deeper and more systematic look to find out what causes this poor quality of sleep among nursing staff. The management should make sure that this issue is solved, so that the nurses and MSWs can work well without being sick. 


\section{Limitations}

There are some drawbacks that are found in this study. This study is cross-sectional in which the data was obtained with the research duration at one point. This data may therefore not be able to fully capture the problems of causal relations between some of the relevant variables.

Secondly, this research would concentrate exclusively on defined variables such as certain physical and mental health issues linked to shift work systems that may be extended to other health conditions such as CV disease, cancer of breast, obesity which can cause various musculoskeletal problems. Thirdly, this research had been carried out at the Tertiary Care Hospitals of Wardha City among Nurses and MSWs. Because of that data gathering findings are not applicable to other classes or occupations. Eventually, due to time constraints, this study's unit of research is based only in the city of Wardha.

\section{Recommendations}

In reviewing breaks, rest periods at night and shift work schedules to improve the working atmosphere of nurses who have rotating shift pattern of duty, this research should be given further thought by hospital management as a guidance to the hospital. Nurses and MSWs should be allowed to take daily day breaks including mealtimes on all shifts.

Apart from that, hospital management should build a variety in schedule of shift work duties and flexibility in time of working or include nurses during non - day shift to meet the safety needs and minimize health outcomes. In addition, administrators should also have a welcoming environment to enable nurses and MSWs to participate in healthy behaviours during rotating shift work. By offering these resources, wellbeing of nurses and MSWs would undoubtedly increase, and health - related outcomes would decrease.

Data sharing statement provided by the authors is available with the full text of this article at jemds.com.

Financial or other competing interests: None.

Disclosure forms provided by the authors are available with the full text of this article at jemds.com.

\section{REFERENCES}

[1] Lohitashwa R, Kadli N, Kisan R, et al. Effect of stress on sleep quality in young adult medical students: a cross sectional study. Int J Res Med Sci 2015;3(12):3519-23.

[2] Da Rocha MCP, De Martino MMF, Ferreira LRC. Stress of the nurses who work on different hospital departments: a descriptive study. Online Brazilian Journal of Nursing 2009;8(3).
[3] Blachowicz E, Letizia $M$. The challenges of shift work. Medsurg Nurs 2006;15(5):274-80.

[4] Sun Q, Ji X, Zhou W, et al. Sleep problems in shift nurses: a brief review and 62 recommendations at both individual and institutional levels. J Nurs Manag 2018;27(1):10-8.

[5] Kim JY, Chae CH, Kim YO, et al. The relationship between quality of sleep and night shift rotation interval. Ann Occup Environ Med 2015;27(1):31.

[6] Thapa D, Malla G, Asim KC. Sleep quality and related health problems among shift working nurses at a tertiary care hospital in Eastern Nepal: a cross-sectional study. J Nurs Health Stud 2018;2(3):1-4.

[7] Kazemi M, Hosieni F, Rezaeian M, et al. Factors associated with quality of sleep of nurses at Raf-sanjan University of Medical Sciences, Iran, in 2013. J Occu Health Epidemiol 2015;4(1):26-33.

[8] Olawale 00, Taiwo OA, Hesham A. Quality of sleep and well-being of health workers in Najran, Saudi Arabia. Indian J Psychiatry 2017;59(3):347-51.

[9] Elsayad HSE, Shazly MM, Mahmoud SI. Nurses perception toward nursing workloads and its effect on nurses errors at Benha University Hospital. Egyptian Journal of Health Care 2017;8(1):53-64.

[10] Van Laethem M, Beckers D, Geurts S, et al. Perseverative cognition as an explanatory mechanism in the relation between job demands and sleep quality. Int J Behav Med 2017;25(2):231-42.

[11] Johannessen H, Sterud T. Psychosocial factors at work and sleep problems: a longitudinal study of the general working population in Norway. Int Arch Occup Environ Health 2017;90(7):597-608.

[12] Chazelle E, Chastang JF, Niedhammer I. Psychosocial work factors and sleep problems: findings from the French national SIP survey. Int Arch Occup Environ Health 2016;89(3):485-95.

[13] Han K, Trinkoff AM, Geiger-Brown J. Factors associated with work-related fatigue and recovery in hospital nurses working 12-hour shifts. Workplace Health Saf 2014;62(10):409-14.

[14] Zhang L, Sun DM, Li CB, et al. Influencing factors for sleep quality among shift-working nurses: a cross-sectional study in china using 3-factor pittsburgh sleep quality index. Asian Nurs Res (Korean Soc Nurs Sci) 2016;10(4):277-82.

[15] Shrivastava D, Jung S, Saadat M, et al. How to interpret the results of a sleep study. J Community Hosp Intern Med Perspect 2014;4(5):24983.

[16] Desjardins S, Lapierre S, Hudon C, et al. Factors involved in sleep efficiency: a population-based study of community-dwelling elderly persons. Sleep 2019;42(5):zsz038. 